\title{
Nuestra revista
}

\author{
"Si he visto lejos es porque estoy sentado sobre los hombros de gigantes". \\ Sir Isaac Newton (1676), parafraseando a Juan de Salisbury (1159). \\ "Toda la cooperación humana a gran escala se basa en nuestra creencia en órdenes imaginados, un conjunto de normas que, \\ a pesar de existir únicamente en nuestra imaginación, creemos que son tan reales e inviolables como la gravedad". \\ Yuval Noah Harari ${ }^{(1)}$
}

No es posible comenzar de otra forma este editorial que agradeciendo a la Dra. María del Pilar Aguilar Passano por su dedicación y profesionalismo al frente del Consejo Editorial de la Revista Uruguaya de Cardiología (RUC) durante los años previos. En mi nombre le profeso el reconocimiento de pasantes, editores asociados y adjuntos, actuales y pasados, testigos de la gran labor desempeñada hasta el fin de su tarea como editora jefa, la cual prosigue ahora como editora anterior y revisora de gran calidad.

Agradezco la oportunidad que se me brinda de conducir este proyecto, que siempre consideré la "joya de la corona" de la Sociedad Uruguaya de Cardiología.

La RUC es sin duda una de las revistas científicas de mayor calidad en Uruguay y ocupa un lugar destacado en tal sentido a nivel regional. Debido a un largo camino transitado por mis predecesores, cuenta con parámetros de calidad envidiables y presencia en índices y repositorios científicos muy prestigiosos, lo que permite que los artículos tengan llegada a decenas de miles de lectores, cifra que en algún artículo supera los 150.000 .

La ciencia cardiológica es una empresa cooperativa inabarcable, que implica generaciones de "científicos" que producen fragmentos más o menos significativos de conocimiento. Así, el objetivo prioritario del autor de un trabajo es la divulgación de su investigación. Es trabajo de la RUC que esto se lleve a cabo con la más amplia difusión y la mayor calidad posible. Para lograrlo cuenta con un proceso que, por un lado, asegura su difusión internacional mediante el cumplimiento de exigentes parámetros, y, por otro, mejora la presentación del producto desde múltiples aspectos: gramatical, estadístico, estético, entre otros.

Para lograr este último objetivo, el manuscrito inicial debe pasar por varias etapas de corrección, que implican el trabajo completamente honorario de miembros del Consejo Editorial, en ocasiones, decenas de horas de dedicación, para llegar a la versión definitiva que se le presenta al autor para su aprobación final. Me atrevo a decir que en todos los casos el documento resultante es sensiblemente de mayor calidad que el inicial.

El presente número cuenta con 17 artículos, todos ellos de destacado valor. Muestra como particularidad ser el primer número en la historia de la RUC que no contará con una edición impresa. Este cambio se materializa por diversas causas. La principal, el elevado costo de impresión y distribución de la edición, que constituía prácticamente el total del presupuesto de la revista. Por contrapartida, se ha optimizado la publicación online y la difusión por medios digitales y redes sociales (fundamentalmente Twitter), con lo que actualmente se multiplica la difusión de los artículos. Anteriormente, cada ejemplar impreso permitía el acceso a la información exclusivamente al portador del mismo, razón última por la que los medios de comunicación científica del primer mundo, día a día, abandonan la impresión de sus publicaciones. 
También será el último número que no esté íntegramente gestionado a través de OJS (Open Journal System), un sistema informático utilizado mundialmente que permite simplificar el proceso editorial ${ }^{(2)}$.

La contribución de los autores con sus trabajos es nuestra materia prima indispensable y la mejora de éstos, la esencia y objetivo de nuestra actividad. Esperamos un creciente entusiasmo en presentar el producto de vuestro trabajo de investigación, revisión u otros, en la RUC. Lo trataremos dedicada y profesionalmente.

La RUC es tuya.

Dr. Gerardo Soca.

Editor jefe

Revista Uruguaya de Cardiología

Gerardo Soca, https://orcid.org/0000-0002-8073-3292

Bibliografía

1. Harari YN. Homo Deus: Breve historia del mañana. Barcelona: Debate; 2016.

2. Open Journal Systems [Internet]. Budapest; 2002 [consulta: 11 Mar 2020]. Disponible en: https://pkp.sfu.ca/ojs/ 